\title{
Effects of the neonatal intensive care unit environment on preterm infant oral feeding
}

This article was published in the following Dove Press journal:

Research and Reports in Neonatology

2 April 2013

Number of times this article has been viewed

\author{
Rita $\mathrm{H}$ Pickler ${ }^{\prime}$ \\ Jacqueline M McGrath ${ }^{2}$ \\ Barbara A Reyna ${ }^{3}$ \\ Heather L Tubbs-Cooley' \\ Al M Best ${ }^{4}$ \\ Mary Lewis ${ }^{3}$ \\ Sharon Cone ${ }^{3}$ \\ Paul A Wetzel ${ }^{5}$ \\ 'Department of Patient Services, \\ Cincinnati Children's Hospital Medical \\ Center, Cincinnati, OH, USA; ${ }^{2}$ School \\ of Nursing, University of Connecticut \\ and Connecticut Children's Medical \\ Center, Hartford, CT, USA; ${ }^{3}$ VCU \\ Medical Center, Children's Hospital \\ of Richmond, Richmond, VA, USA; \\ ${ }^{4}$ School of Dentistry, ${ }^{5}$ School of \\ Engineering, Virginia Commonwealth \\ University, Richmond, VA, USA
}

Correspondence: Rita H Pickler Department of Patient Services, Cincinnati Children's Hospital Medical Center, 3333 Burnet Ave, Cincinnati, $\mathrm{OH} 45229$, USA

Tel +I 3155035064

$\mathrm{Fax}+\mathrm{I} 315$ 636-9765

Email rita.pickler@cchmc.org
Objective: To examine the effect of neonatal intensive care unit environmental characteristics (perceived levels of light and sound, and time of day) in open unit wards and single-family rooms (SFRs) on oral feeding outcomes in preterm infants.

Design: Data were collected at each scheduled oral feeding for 87 preterm infants from the first oral feeding until discharge. Data included the prescribed volume of feeding and the volume consumed, the infant's level of wakefulness before feeding, and the nurse's perception of light and sound.

Results: Data were collected on 5111 feedings in the ward unit and 5802 in the SFR unit from feedings involving 87 preterm infants. Light and sound were rated significantly lower in the SFR ( $\chi^{2}=139$ and 1654.8, respectively). Feeding times of 9 am, 12 noon, and 3 pm were associated with the highest perceived levels of light and sound, regardless of unit design $(P<0.0001)$. Moderate light levels and feeding times of 12, 3, and 6 am were associated with improved feeding outcomes. Infants consumed a greater proportion of their prescribed feeding volume when fed in the open ward and when awake before feeding.

Conclusion: Further study on the clinical effects of unit design is needed, as is study on the effects of environmental stimuli, so that interventions can be appropriately developed and tailored for infants needing the most support for optimal development.

Keywords: NICU design, clinical outcomes, environment

\section{Introduction}

There is a growing transition in neonatal intensive care unit (NICU) design from the traditional multibed, open-bay nursery to a single family room (SFR) or private room design. ${ }^{1-4}$ Many NICUs have been redesigned from multipatient wards to SFR design with the expectation of improved patient outcomes. In fact, there is some evidence that SFR designs may have benefits for preterm infants and their families, such as greater satisfaction with care and appreciation for the greater privacy and comfort afforded by the SFR design. ${ }^{2,5,6}$ There is also evidence that the SFR room design potentially benefits NICU staff by moderating the effects of the stressful work environment. ${ }^{7,8}$ Moreover, there is emerging evidence that safety outcomes are improved in the SFR setting, including lower sepsis rates and more optimal clinical outcomes. ${ }^{3,9}$ Other potentially meaningful advantages of SFR design include positive physiologic effects of reduced light and sound on infant development. ${ }^{10}$ However, the evidence for the direct effects of this environmental design on the preterm infant is not well established.

Over the years, the effects of light and sound (noise) levels on preterm infants have been studied extensively. ${ }^{11,12}$ It is generally accepted that a dimmer, quieter 
environment is important for the developing brain. Some reported effects of continuous high light exposure on the preterm infant include retinal damage, disturbance of sleep patterns, disturbed development of circadian rhythms, and poor growth. ${ }^{13}$ Bright light has been associated with increased metabolic rates in prematurely born infants, with resultant poor weight gain. In the same vein, noise has been associated with many adverse effects in infants in the NICU, especially in preterm infants with extended stays. ${ }^{14}$ High levels of sound in the NICU may lead to hearing impairments, sleep disturbance, physical illness, and delays in development in preterm infants. Studies have shown that high levels of sound may induce physiological instability in infants, including fluctuations in heart rate, blood pressure, perfusion and oxygen saturation, increases in intracranial pressure, and alterations in corticosteroid levels. ${ }^{15-17}$ Although the effects of excessive light and sound can be detrimental to the developing neonate in a number of ways, the effect of light and sound on routine care such as feeding is not known. Thus, the purpose of this analysis was to examine the differential effects of NICU environmental characteristics (nurses' perceived levels of light and sound, and time of day) associated with traditional open NICU wards and SFR design on oral feeding outcomes (proportion of prescribed oral feeding consumed) in preterm infants.

\section{Methods and materials}

The data for this analysis were gathered as part of a larger randomized control trial in which infants were randomly assigned to one of four feeding approaches to the initiation and progression of oral feedings in preterm infants. The study was approved by the institutional review board, and parents gave written informed consent for their infants' participation.

\section{Research settings}

The open ward unit in which the study was started in January 2007 was designed in the 1970s and opened in the 1980s; it consisted of two large rooms accommodating about 22 infants in each, and a small transitional nursery that held eight babies. Over the years, the unit had been renovated several times, including removing the noisiest of workstation activities to an area between the rooms that allowed noise and light blocking, the addition of bedside lighting to minimize the use of continuous overhead bright lighting, the elimination of overhead paging systems, and the institution of "quiet hour" several times a day, during which time activity in the unit was minimized and the infants were undisturbed.
Flow of traffic and visitors were diverted through a common reception area, and alternate access areas directly into the nurseries were restricted for emergencies or movement of infants off the floor for procedures. However, even with these changes, control of light and sound remained a concern. Infants' incubators were in close proximity to each other and back to back on a free-standing head wall that led to high environmental stimulation from adjacent patient-care activities and monitoring alarms. Parents were left with little room at the bedside.

When the institution proposed building a critical care tower in the early 2000s, the NICU leadership persuaded hospital administrators and funders to include a new NICU in the tower that would take advantage of what was then known about environmental effects on preterm infants. The new unit, which opened in October 2008, has 32 beds in single rooms and four "double" rooms that can accommodate twins. There are several "regionally" located nurses' stations. Technology that provides nursing staff with easy access to assess the status of any infant throughout the nursery without leaving another patient's room was built into the design. Each infant bed space, including those in twin rooms, is set up so that light can be carefully controlled with adjustable direction and dimming capability. Outboard rooms - those with exterior windows - allow for natural lighting; inboard rooms for those extremely preterm infants do not have windows, thus limiting natural lighting. Sound can be controlled by closing the sliding glass doors to each room. Further noisereduction strategies were incorporated using rubberized flooring, acoustical ceiling tiles, and ceramic as opposed to stainless steel sinks. Rooms also include easy operation, pullout beds for parents. Supply carts as well as ergonomically designed parent chairs are equipped with rollers to decrease unnecessary noise.

\section{Procedures and measures}

Infants were enrolled in the study when they were 30-32 weeks postmenstrual age (PMA). Once oral feedings were initiated based on the assigned feeding approach, data were collected at each scheduled feeding (generally eight feedings per day) using a paper-and-pencil data-collection form with time of feeding noted. These data included information about the prescribed volume of feeding and the volume consumed, the infant's state of wakefulness before and after the feeding, and the level of environmental light and sound as perceived by the infant's assigned nurse. The feeding outcome of interest for this analysis - proportion consumed - was computed from volume prescribed and 
volume taken orally at each feeding. Light and sound were rated by the assigned nurse using a Likert scale, where 1 was the lowest level and 5 the highest level perceived. Wakefulness was recorded as "yes" or "no." Time of day at which the feeding occurred was also recorded. The datarecording form was created by the investigators in order to record simply the environmental context within which feedings occurred. The nursing staff received training in the use of the recording tools, including gauging light and sound levels and assessment of wakefulness (ie, eyes open or closed, active body movements, facial expressions). Daily contact with the nursing staff occurred throughout the study to ensure the staff were recording the data and any questions about form completion. Periodic assessment of tool use occurred throughout the study. Unit nurses were trained by the study team to collect and record the data on study documents. Demographic data were collected by the research staff, including sex, morbidity, and maturity. Data were collected about infant morbidity using the Neonatal Morbidity Index (NMI), a summary measure that accounts for infant birth weight as well as respiratory illness and oxygen use and other illnesses. ${ }^{18}$ Data about maturity were collected using several measures, including PMA, day of life, and the Neurobehavioral Maturity Assessment scale. ${ }^{19}$ All maturity values were highly correlated, so PMA was used as the measure of maturity in the analyses.

All data were manually entered by trained data-entry personnel into a secure database. Data were checked for completeness and accuracy using a system of quarterly data audits and statistical assessments. Data were analyzed using descriptive statistics, Chi-square, and logistic regression repeated-measures modeling. Percent consumed, the primary outcome, was scaled into a bound variable. Predictor variables were added to the model along with interaction terms of known interest. Backward stepwise methods were used to choose an adequate model to fit data. All tests were done at significance level alpha $=0.05$. We assumed that an autoregressive covariance pattern existed in time of day within each day for each subject. To simplify the model, we assumed that measures on a different day for a single subject were independent. Observations from different subjects were also independent from each other.

\section{Results}

Data for the analysis were collected over 4 years from 2007 to 2010. Data were collected on 10,913 individual feedings involving 87 preterm infants; 5111 feedings occurred in the original ward unit and 5802 occurred in the SFR unit.
The sample included 87 preterm infants: 43 males, 44 females. The average birth weight was $1400 \mathrm{~g}$, and the average birth gestation was 29 weeks +5 days. The sample was $70 \%$ black/African American. There were 34 infants who were relatively well $(\mathrm{NMI}=1$ or 2$), 25$ infants who scored as moderately ill $(\mathrm{NMI}=3)$, and 18 infants who scored as most ill (NMI $=4$ or 5$)$. The median number of observations per infant was 92 (range 1-331). There were no differences in birth gestation, birth weight, or morbidity between infants observed in the open ward and those observed in the SFR unit.

Light and sound were significantly correlated at $r=0.43$ $(P \leq 0.01)$. Light and sound were rated significantly lower in the SFR versus the ward using chi-square analysis $\left(\chi^{2}=139\right.$ and 1654.8, respectively; $P<0.0001$ for both comparisons), as seen in Table 1. Time of day at which the feeding occurred had an effect on light and sound. The feeding times of $9 \mathrm{am}$, 12 noon, and 3 pm were associated with the highest perceived levels of light and sound regardless of unit design, with both measures significantly higher in the ward $(P<0.0001)$ than in the SFR at all feeding times.

A prediction model was developed to examine differences in the primary outcome measure, proportion consumed. Although many factors may affect infant feeding, for this analysis we included those factors that have been found in previous research to affect feeding performance outcomes, such as proportion consumed. These factors include infant sex, morbidity, maturity, and infant wakefulness prior to feeding. The primary measures for this analysis were also added, including nursery type, light, and sound. We additionally included time of feeding in the analysis, as it had an effect on the primary measures of light and sound. As Table 2 shows, sex, morbidity, and maturity were significant

Table I Differences in light, sound, and activity by unit type

\begin{tabular}{|c|c|c|}
\hline Rating & $\begin{array}{l}\text { Light* } \\
\text { n (\%) }\end{array}$ & $\begin{array}{l}\text { Sound* } \\
\text { n (\%) }\end{array}$ \\
\hline \multicolumn{3}{|l|}{ Ward } \\
\hline I (lowest) & $325(6)$ & $230(4)$ \\
\hline 2 & $3563(70)$ & $3300(65)$ \\
\hline 3 & $1096(21)$ & |37| (27) \\
\hline 4 & $99(2)$ & $188(3)$ \\
\hline 5 (highest) & $23(1)$ & $15(1)$ \\
\hline \multicolumn{3}{|l|}{ SFR } \\
\hline I & $428(7)$ & $892(15)$ \\
\hline 2 & 4578 (79) & 4739 (82) \\
\hline 3 & $722(12)$ & $170(3)$ \\
\hline 4 & $63(1)$ & 2 \\
\hline 5 & II (I) & 0 \\
\hline
\end{tabular}

Note: *Significant at $P<0.000 \mathrm{I} . \mathrm{n}=$ the number of times each rating was observed. Abbreviation: SFR, single family room. 
Table 2 Effect of predictors on proportion consumed

\begin{tabular}{llllll}
\hline Effect & df & B & SEB & t-ratio & P-value \\
\hline Sex (female) & I & 5.59 & 0.32 & 17.50 & $<0.000$ I \\
Morbidity (NMI 2) & I & 3.43 & 0.66 & 5.17 & $<0.000$ I \\
Maturity ( $>34$ weeks) & 4 & 12.83 & 0.34 & 37.86 & $<0.000$ I \\
Nursery type (SFR) & $\mathrm{I}$ & -2.65 & 0.37 & -7.13 & $<0.000$ I \\
Time of feeding (I2 am) & 7 & $3.9 \mathrm{I}$ & 0.70 & 4.95 & $<0.000$ I \\
Light (3, moderate) & 4 & 5.08 & 1.36 & 3.72 & $<0.0002$ \\
Sound (3, moderate) & 4 & $-0.8 \mathrm{I}$ & 2.13 & -0.38 & 0.70 \\
Wakefulness before & $\mathrm{I}$ & 6.65 & 0.38 & 17.64 & $<0.000 \mathrm{I}$ \\
feeding (awake) & & & & &
\end{tabular}

Notes: $R^{2}=0.21$; F ratio $=91.41 ; P<0.001$.

Abbreviations: $\mathrm{df}$, degrees of freedom; $\mathrm{B}, \beta$ estimate; SEB, standard error $\beta$; NMI, Neonatal Morbidity Index; SFR, single family room.

predictors of the feeding outcomes. Female infants consumed more than male infants ( $71 \%$ versus $60 \%)$, healthier infants consumed more than sicker infants (65\% versus $61 \%)$, and more mature infants consumed more than less mature infants (78\% versus $52 \%$ ). As the table also shows, unit type was also a significant predictor, with consumption in the traditional ward unit averaging $68 \%$ compared to $63 \%$ in the SFR. Time of day also predicted the proportion consumed: feedings at 12 am averaged $70 \%$ versus $63 \%$ at 9 am. Light was also predictive: a greater proportion was consumed when the feeding environment was darker (74\% versus 64\%). Additionally, infants consumed a greater proportion of the feeding when they were awake at the start of the feeding (72\% versus $59 \%)$.

\section{Discussion}

Preterm infant feeding is affected by many things, including specific characteristics of the infant. ${ }^{20}$ In this analysis, we found that an oral feeding outcome - percent consumed - was affected by characteristics particular to the infant, such as sex and morbidity as well as infant wakefulness at the start of feeding and time of day the feeding occurred. In particular, we found that the percent of prescribed volume consumed was greater for female infants, for infants who were less ill, and for infants who were over 34 weeks PMA. We also found that when infants were awake at the start of the feeding, they consumed a greater proportion of the prescribed volume. Moreover, the very early morning feedings (12 am, $3 \mathrm{am}$, and $6 \mathrm{am}$ ) resulted in a greater proportion of prescribed volume consumed versus those feedings that occurred at $9 \mathrm{am}, 12 \mathrm{pm}$, and $3 \mathrm{pm}$. Oral feeding is also influenced by environmental characteristics that can be modified. In this analysis, we also found that infant oral feeding was significantly improved by moderate light levels. However, despite a perception that light and sound levels were lower in the
SFR unit than in the open ward, infants did not necessarily consume a greater proportion of the prescribed oral feeding volume when fed in the SFR. Rather, consumption was greater in the open ward unit.

Several conclusions can be drawn from this analysis. First, there is much about preterm infant feeding that is not directly amenable to intervention. For example, male preterm infants have a reputation, some of which is supported in the literature, of having worse clinical outcomes than female infants. ${ }^{21}$ In addition, despite great strides in preterm treatment and care, some infants are quite ill and remain so for some time. Most notable are those infants that require long-term oxygen support, which is known to have a negative effect on feeding skill progression. ${ }^{22}$ Maturity is another characteristic that cannot be rushed; infants progress in oral feeding along a somewhat well-known trajectory. Moreover, despite some evidence that increased oral feeding experience will result in more rapid oral feeding skill acquisition, it remains the case that more mature preterm infants will feed better than less mature infants. ${ }^{20,23}$ Thus, from an intervention perspective, there is little that can be changed about these infant characteristics.

However, the findings of this analysis do support a relatively well-established understanding that preterm infant level of wakefulness before the feeding results in better feeding outcomes. ${ }^{24,25}$ This addresses the continued need to teach those who are feeding the infants, including nurses, therapists, and parents, to assess infant behavior state. If there is a question about wakefulness, there are gentle interventions, such as offering a pacifier for nonnutritive sucking that will help bring the infant to a more robust state of wakefulness within a few minutes. ${ }^{24,26,27}$ Unfortunately, level of wakefulness can be difficult to assess, especially in bright lights and a noisy environment, when an infant may keep his or her eyes closed in order to block extraneous stimuli. Thus, determination of level of wakefulness requires assessment in an environment where the infant can best exhibit those signs of wakefulness that are most recognizable to the feeder, ie, an environment that is quiet and of low direct light.

Light was shown to affect feeding outcomes in this analysis, as was time of day at which the feeding occurred. Unfortunately, lighting may be difficult to control in many NICUs, particularly those that were built prior to our increased understanding of the effect of the environment on preterm infant outcomes. However, it may be possible to control some light in the immediate feeding area. Localized, adjustable, and dimmable lighting might be used whenever possible, as well as other strategies that might minimize the 
amount of direct light exposures, such as feeding the infant from behind a portable screen, an item used in many wardstyle NICUs to provide privacy for families. Interventions to reduce lighting in the feeding area may be particularly important for less mature and less well preterm infants. Just attending to these controllable aspects of the environment may result in "better" feeding performance and perhaps easier transition to full oral feeding and the discharge to home.

The time of day at which a feeding occurred also affected feeding outcomes in this analysis, with the busiest daytime hours having a significantly negative effect on oral consumption. The finding that the nurseries were brighter and louder at particular times of the day is consistent with the findings reported in other studies. ${ }^{10,14,17}$ Some unit practices may contribute to this environmental characteristic, including bedside rounds, clustering of care, and multiple assessments conducted within a short time interval. The effect of these activities on immediate and longer-term neurodevelopmental outcomes needs further study to determine their effects on important health outcomes. In the meantime, an interesting intervention to consider might be the initiation and trial of oral feedings at those less busy times of the day when both light and sound are generally at lower levels, as opposed to those times of the day most closely associated with brighter light and higher sound levels. The interaction of time of day with the environmental characteristics is important to consider, especially perhaps when an infant is first making a transition to oral feeding.

The growing number of NICUs moving toward an SFR design is astounding. Although there have been some analyses of these units and evaluations of parent and staff satisfaction, the effect of unit design on clinical outcomes is not well studied. This analysis failed to show that the SFR design had a superior effect on a particular measure of preterm infant oral feeding. Further study on the clinical effects of unit design is needed, as is study on the effects of environmental stimuli, so that interventions can be appropriately developed and tailored for infants needing the most support for optimal development. For example, there is emerging evidence that cycled lighting may be supportive of preterm infant development. ${ }^{28}$ However, a recent Cochrane review found only five small studies comparing cycled lighting to near-dark or dim lighting. ${ }^{13}$ That review reported no difference in weight gain or the incidence of retinopathy of prematurity. Trends favoring the effects of cycled lighting on activity and sleep were found. Further research on lighting interventions is needed. Moreover, as new care delivery systems are developed, research that measures the effects of those delivery systems on important clinical outcomes, such as feeding skill development, should also be considered a priority.

\section{Limitations}

Despite the large number of observations included in this analysis and statistical analysis that accounted for the repeated-measure nature of the data, there are limitations to the data and thus its interpretation. The study, while involving two types of unit design, was conducted in a single health-care facility with the same staff members and policies regarding oral feeding of preterm infants in both unit types. Second, data used for the analysis were nurses' reported perceptions of light and sound, as well as nurses' perceptions of infants' level of wakefulness. Although nurses were trained in use of the data forms, it is possible that some nurses' perceptions of these environmental conditions might differ from other nurses' perceptions. Certainly, the use of electronic devices for light and sound would have resulted in very precise measurements for these variables. However, since the measurement of light and sound was not a primary aim of the study, we did not use those types of devices. Additionally, we included in our analysis three sets of twins who were, after the move to the SFR unit, located in the same family room. This approach to SFRs may differ in other units that are strictly one infant per room. While it is the case that for this very small subset, the assessments of light and sound were similar, level of wakefulness was not. Because the number of twin sets was small and because outcomes did not differ in our analysis when twins were excluded, we left them in the analysis. However, we recognize that light and sound levels may affect feeding outcomes differently for infants in true single rooms. Finally, we used as a primary outcome measure here proportion consumed. This is only one feeding "performance" outcome, and it may not be the most important one. However, it is arguably the clinical outcome of greatest importance to both clinicians and parents, as proportion consumed eventually becomes the indicator of "feeding competence," and thus a primary indicator for discharge-to-home readiness.

\section{Acknowledgments}

The study was support in part by R01 NR005182 (Pickler) and R15 NR09235 (McGrath) both from the National Institute of Nursing Research, National Institutes of Health.

\section{Disclosure}

The authors report no conflicts of interest in this work. 


\section{References}

1. Milford CA, Zapalo BJ, Davis G. Transition to an individual-room NICU design: process and outcome measures. Neonatal Netw. 2008;27: 299-305.

2. Carter BS, Carter A, Bennett S. Families' views upon experiencing change in the neonatal intensive care unit environment: from the 'baby barn' to the private room. J Perinatol. 2008;28:827-829.

3. Walsh WF, McCullough KL, White RD. Room for improvement: nurses' perceptions of providing care in a single room newborn intensive care setting. Adv Neonatal Care. 2006;6:261-270.

4. Cone SK, White RD. Single family room design in the newborn intensive care unit. In Kenner C, McGrath JM, editors. Developmental Care of Newborns and Infants. Glenview (IL): National Association of Neonatal Nurses; 2010.

5. Shahheidari M, Homer C. Impact of the design of neonatal intensive care units on neonates, staff, and families: a systematic literature review. J Perinat Neonatal Nurs. 2012;26:260-266.

6. Domanico R, Davis DK, Coleman F, Davis BO. Documenting the NICU design dilemma: parent and staff perceptions of open ward versus single family room units. J Perinatol. 2010;30:343-351.

7. Stevens DC, Helseth CC, Khan MA, Munson DP, Smith TJ. Neonatal intensive care nursery staff perceive enhanced workplace quality with the single-family room design. J Perinatol. 2010;30:352-358.

8. Cone SK, Short S, Gutcher G. From "baby barn" to the "single family room designed NICU": a report of staff perceptions one year post occupancy. Newborn Infant Nurs Rev. 2010;10:97-103.

9. Erickson C, Kattelmann K, Remington J, Ren C, Helseth CC, Stevens DC. Traditional open-bay versus single-family room neonatal intensive care unit: a comparison of selected nutrition outcomes. Res Reports Neonatol. 2011;1:15-20.

10. Chen H, Chen C, Wu C, Huang H, Wang T, Hsu C. The influence of neonatal intensive care unit design on sound level. Pediatr Neonatol. 2009;50:270-274.

11. Byers J, Waugh W, Lowman L. Sound level exposure of high-risk infants in different environmental conditions. Neonatal Netw. 2006;25: 25-32.

12. Peng N, Bachman J, Jenkins R, Chen C, Chang Y, Wang T. Relationships between environmental stressors and stress biobehavioral responses of preterm infants NICU. J Perinat Neonatal Nurs. 2009;23:363-371.

13. Morag I, Ohlsson A. Cycled light in the intensive care unit for preterm and low birth weight infants. Cochrane Database Syst Rev. 2011;1:CD006982.

14. Darcy AE, Hancock LE, Ware EJ. A descriptive study of noise in the neonatal intensive care unit. Ambient levels and perceptions of contributing factors. Adv Neonatal Care. 2008;8:165-175.
15. Graven SN. Sound and the developing infant in the NICU: conclusions and recommendations for care. J Perinatol. 2000;20:S88-S93.

16. Bremmer P, Byers JF, Kiehl E. Noise and the premature infant: physiological effects and practice implications. J Obstetr Gynecol Neonatal Nurs. 2003;32:447-454.

17. Matook SA, Sullivan MC, Salisbury A, Miller RJ, Lester BM. Variation of NICU sound by location and time of day. Neonatal Netw. 2010;29:87-95.

18. Korner AF, Stevenson DK, Kraemer HC, et al. Prediction of the development of low birth weight preterm infants by a new neonatal medical index. J Dev Behav Pediatr. 1993;14:106-111.

19. Korner AF, Kraemer HC, Reade EP, Forrest T, Dimiceli S, Thom VA. A methodological approach to developing an assessment procedure for testing the neurobehavioral maturity of preterm infants. Child Dev. 1987;58:1478-1487.

20. Pickler RH, Best AM, Reyna BA, Wetzel PA, Gutcher GR. Prediction of feeding performance in preterm infants. Newborn Infant Nurs Rev. 2005;5:116-123.

21. Kent AL, Wright IM, Abdel-Latif ME. Mortality and adverse neurologic outcomes are greater in preterm male infants. Pediatrics. 2012;129:124-131.

22. Jadcherla SR, Wang M, Vijayapal AS, Leuthner SR. Impact of prematurity and co-morbidities on feeding milestones in neonates: a retrospective study. J Perinatol. 2010;30:201-208.

23. Medoff-Cooper B, Bilker W, Kaplan M. Suckling behavior as a function of gestational age: a cross-sectional study. Infant Behav Dev. 2001;24:84-94.

24. McCain GC, Gartside P, Greenberg JM, Lott JW. A feeding protocol for healthy preterm infants that shortens time to oral feeding. J Pediatr. 2001;139:374-379.

25. McGrath JM, Medoff-Cooper B. Alertness and feeding competence in extremely early born preterm infants. Newborn Infant Nurs Rev. 2002;2:174-186.

26. Pickler RH, Frankel HB, Walsh KM, Thompson N. Effects of nonnutritive sucking on behavioral organization and feeding performance in preterm infants. Nurs Res. 1996;45:132-135.

27. Pickler RH, Reyna BA. Effects of nonnutritive sucking on nutritive sucking, breathing, and behavior during bottle feedings of preterm infants. Adv Neonatal Care. 2004;4:226-234.

28. Rivkees SA, Mayes L, Jacobs H, Gross I. Rest-activity patterns of premature infants are regulated by cycled lighting. Pediatrics. 2004;113: 833-839.
Research and Reports in Neonatology

\section{Publish your work in this journal}

Research and Reports in Neonatology is an international, peer-reviewed, open access journal publishing original research, reports, editorials, reviews and commentaries on neonatal health. The manuscript management system is completely online and includes a very quick and fair

\section{Dovepress}

peer-review system. Visit http://www.dovepress.com/testimonials.php to read real quotes from published authors. 